\title{
Inactivation of $\alpha$-Amylase by Caffeine: Reducing the Break-down of Starch into Sugars
}

\author{
Neel Rajan, Stephen James Koellner, Vincent Todd Calabrese, Arshad Khan* \\ Department of Chemistry, Pennsylvania State University, Du Bois, PA 15801, USA \\ Email address: \\ kub@psu.edu (A. Khan) \\ ${ }^{*}$ Corresponding author

\section{To cite this article:} \\ Neel Rajan, Stephen James Koellner, Vincent Todd Calabrese, Arshad Khan. Inactivation of $\alpha$-Amylase by Caffeine: Reducing the \\ Break-down of Starch into Sugars. American Journal of Bioscience and Bioengineering. Vol. 6, No. 1, 2018, pp. 1-4. \\ doi: 10.11648/j.bio.20180601.11
}

Received: December 23, 2017; Accepted: December 28, 2017; Published: January 11, 2018

\begin{abstract}
Amylase, an enzyme present in our saliva and pancreatic secretion, is responsible for the break-down of starch into glucose molecules. Glucose enters into our blood steam and provides energy for various activities. In this study we have noticed that in the presence of caffeine, the enzyme activity is decreased with a decrease in the amount of glucose liberated from the starch hydrolysis. This finding suggests a positive role played by caffeine in the controlling of blood sugar. A possible explanation of enzyme inactivation by caffeine has been discussed in terms of a two-step model that we proposed earlier.
\end{abstract}

Keywords: Caffeine-Amylase Interaction, Inactivation of $\alpha$-Amylase by Caffeine, Reducing the Starch Hydrolysis by Caffeine

\section{Introduction}

$\alpha$-Amylase is an enzyme that helps in the break-down of starch into glucose molecules and aids in the digestion process. It has a molecular weight of around 50000 , and contains at least $1 \mathrm{~mol}$ of calcium ion per mole of protein, and has been extensively studied [1-7]. Although this enzyme has been isolated from various sources like bacterial species (bacillus), fungal and other animal sources, it exhibits very similar characteristics, like rapid fragmentation of starch molecules to reducing sugars, inactivation by an initial dissociation of $\mathrm{Ca}^{2+}$ ions followed by denaturation by heat $(8$, 9), etc. Denaturation is the unfolding of the enzyme tertiary structure to a disordered polypeptide in which key residues are no longer aligned closely for stabilizing interactions [10].

Among the experimental conditions that may cause inactivation; temperature, $\mathrm{pH}$, chemical agents, solvent type (aqueous-non-aqueous), etc. are well-known. We already examined some of these experimental conditions on $\alpha$ amylase activity and its inactivation rates in aqueous solutions $[8,9,11]$. Among the chemical agents, we tried both neutral as well as ionic species and examined their influence on the enzyme activity. In this work we examined the effect of caffeine concentration on the enzyme activity. Since our primary objective was to learn the effect of caffeine on the enzyme, we held the temperature fixed at a relatively lower value $\left(25^{\circ} \mathrm{C}\right)$ so as to ensure that the inactivation effect due to heat is negligible.

\section{Theory of Inactivation of $\alpha$-Amylase}

The inactivation reaction of $\alpha$-amylase takes place in two stages [8]. The first reversible stage (eq 1) involves a forward reaction that forms an inactive apoenzyme, $\mathrm{E}^{2-}$, from the active enzyme, $\mathrm{CaE}$, with a rate constant of $\mathrm{k}_{1}$ and a reverse reactivation reaction involving the combination of $\mathrm{E}^{2-}$ with calcium ions with a rate constant of $\mathrm{k}_{-1}$. The second irreversible stage (eq 2) of reaction forms a denatured form of the enzyme, $\mathrm{EI}^{2-}$, from $\mathrm{E}^{2-}$ with a rate constant of $\mathrm{k}_{2}$.

$$
\begin{gathered}
\mathrm{CaE} \underset{k_{-1}}{\stackrel{k_{1}}{\rightleftharpoons}} \mathrm{Ca}^{2+}+\mathrm{E}^{2-} \\
\mathrm{E}^{2-} \stackrel{k_{2}}{\rightarrow} \mathrm{EI}^{2-}
\end{gathered}
$$

On the basis of these inactivation steps the following equations for enzyme inactivation can be written: 


$$
\mathrm{XD}=1-e^{-k_{3} \mathrm{t}}
$$

Where,

$$
k_{3}=1-\frac{k_{1} k_{2}}{k_{-1}\left[\mathrm{Ca}^{2+}\right]+k_{2}}
$$

The expression XD (eqn 3 ) gives the fraction of enzyme inactivated at a certain time, $t$, after the inactivation process begins, and $\mathrm{k}_{3}$, given by equation 4 , is a function of calcium ion concentration, and rate constants, $\mathrm{k}_{1}, \mathrm{k}_{-1}$, and $\mathrm{k}_{2}$ and hence, a function of temperature. From the expression 3 one can readily obtain the value of percent active enzyme as follows:

$$
\text { Percent Active Enzyme }=(1-\mathrm{XD}) 100=100 e^{-k_{3} \mathrm{t}}
$$

A more detailed derivation of equation 3 (and hence, eqn 5) can be found in reference 8 , and various results showing validity of the two-step model are presented in references 8 , 9 and 11. These test cases involve various additives to the enzyme, which include organic, inorganic, ionic-non-ionic substances together with the aqueous-nonaqueous mixed solvents.

\section{Methods and Materials for Inactivation Studies of $\alpha$-Amylase with Caffeine}

\subsection{Preparation of Solutions}

\section{Enzyme solutions}

Bacterial $\alpha$-amylase concentrate was prepared by adding $2.1 \mathrm{mg}$ of bacterial $\alpha$-amylase to $42 \mathrm{~mL}$ of distilled water (A6380, Sigma Chemical Co.). Human $\alpha$-amylase concentrate was prepared by adding $3.0 \mathrm{mg}$ of human $\alpha$ amylase (A1031, Sigma Chemical Co.) to $12.2 \mathrm{~mL}$ of distilled water. The diluted enzyme solutions were made from this solution during experiments. The $\mathrm{pH}$ of the solution was maintained at 4.0 by adding acetic acid-acetate buffer solution (Fisher Scientific).

Iodine solution: The cold iodine solution (around $2^{\circ} \mathrm{C}$ ) of $126.9 \mathrm{mg} / \mathrm{L}$ was made from a solution containing the same volume each of $0.05 \mathrm{M}$ iodine solution and $5 \%$ potassium iodide solution (Fisher Scientific).

Amylose solution: The amylose solution $(\sim 1.50 \mathrm{~g} / \mathrm{L})$ was made by first dissolving potato amylose (Sigma Chemical) in $2 \mathrm{M} \mathrm{NaOH}$ solution followed by the addition of an equal volume of $2 \mathrm{M} \mathrm{HCl}$ and then heating to a clear solution before adjusting its $\mathrm{pH}$ by adding acetic acid-acetate buffer solution. Dilute solutions of $0.186 \mathrm{~g} / \mathrm{L}$ were prepared during experiments.

\subsection{Activity Measurements}

Activity is measured at $25^{\circ} \mathrm{C}$ by allowing the enzyme to react with an amylose solution $(0.186 \mathrm{~g} / \mathrm{L})$ for $2 \mathrm{~min}$ before stopping the reaction with a cold iodine solution, which converts unhydrolyzed amylose into amylose - iodine (AI) or starch - iodine blue complex (absorbance peak at $615 \mathrm{~nm}$ ). As was established before $[8,9]$, the addition of iodine not only provides information about the amount of unhydrolyzed amylose, it also stops the enzymatic hydrolysis reaction. The resulting solution was then placed in a thermostated bath for $10 \mathrm{~min}$ to reach $25^{\circ} \mathrm{C}$ before measuring its absorbance at 615 nm. A more active enzyme leaves behind a smaller amount of unhydrolyzed amylose, and hence, gives a smaller absorbance value at $615 \mathrm{~nm}$. On the other hand, an inactivated enzyme will have a larger amount of unhydrolyzed amylose and will give a larger absorbance value at $615 \mathrm{~nm}$.

\subsection{Inactivation Experiments with Caffeine}

The concentrations of caffeine in the $\alpha$-amylase solutions range from $0.00 \%-0.30 \%$ with an increment of $0.05 \%$. The enzyme solutions were prepared by adding $6.85 \mathrm{~mL}$ of concentrated protein $(1.60 \mu \mathrm{M}), 1 \mathrm{~mL}$ of $\mathrm{pH} 4.0$ buffer, desired amount of caffeine, and water for a total volume of $100 \mathrm{~mL}$ in a volumetric flask, and was kept at $25^{\circ} \mathrm{C}$. For each caffeine concentration, an aliquot of the protein solution was withdrawn before determining its activity by adding the amylose solution. A blank test was done by leaving out enzyme from the solution, and its absorbance reading was taken (at $615 \mathrm{~nm}$ and $25^{\circ} \mathrm{C}$ ) after adding cold iodine, followed by warming to $25^{\circ} \mathrm{C}$, as was discussed under the previous section. The blank value is proportional to the initial amylose concentration (before the enzymatic hydrolysis) and was used in the calculations of protein activity values. In these studies, the $\mathrm{pH}$ of 4.0 was selected as the starch iodine method, applied for activity measurements, shows high sensitivity at this $\mathrm{pH}$. Besides, we wanted to examine the effect of caffeine in an acidic solution. In the future we plan to study the effect of caffeine at a higher $\mathrm{pH}$ (7.4, blood $\mathrm{pH})$ so that we can examine how the effect of caffeine changes as the $\mathrm{pH}$ is increased.

\section{Results \& Discussions}

Figure 1 represents caffeine concentration vs. absorbance values at $615 \mathrm{~nm}$. Each inactivation experiment was repeated at least 3 times, and the results were within $3 \%$ of those presented in Figure 1. The four curves represent four different enzyme concentrations ranging from 0.15 to 0.45 $\mathrm{mg} / \mathrm{L}$. Each curve shows an increasing trend in the absorbance values, and suggests a gradual inactivation of the enzyme with an increased caffeine concentration that leaves behind a larger quantity of unhydrolyzed amylose, and hence, a larger absorbance value in iodine solution. The absorbance values, presented in Figure 1, are converted into the percent active enzyme by applying eqns. 6 and 7 . In eqn $6, \mathrm{~A}_{0}$ is the absorbance value in the absence of enzyme (blank), $\mathrm{A}$ is the absorbance value in the presence of the enzyme with varied amount of caffeine (0-0.3\% caffeine), and $\mathrm{AH}$ represents the percent amylose hydrolyzed in 2 minutes of reaction time applied for activity measurements. 


$$
\mathrm{AH}=\left(\frac{A_{\circ}-A}{A_{\circ}}\right) 100
$$

Percent active $=\left(\frac{A H_{t}}{A H_{\mathrm{o}}}\right) 100=(1-\mathrm{XD}) 100$

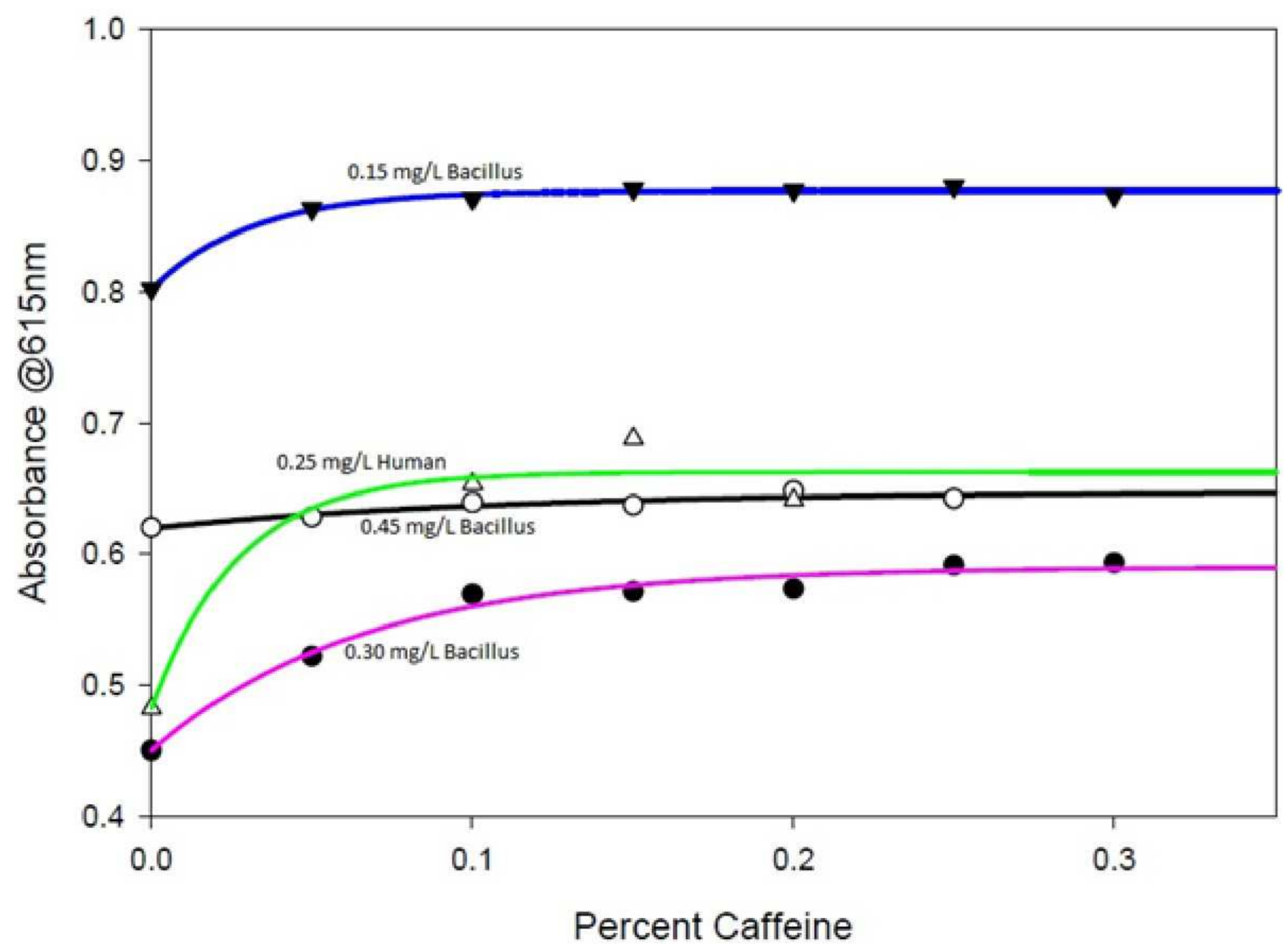

Figure 1. Percent caffeine against Absorbance values at $615 \mathrm{~nm}$ are plotted for different enzyme concentrations.

In eqn 7, the $\mathrm{AH}_{0}$ represents the percent of amylose hydrolyzed by the fully active enzyme (no caffeine being added), and $\mathrm{AH}_{\mathrm{t}}$ represents the amount of amylose hydrolyzed due to an inactivated enzyme as a result of the addition of caffeine. This is how Figure 2 was obtained from the absorbance values of Figure 1, and represents percent active enzyme for different caffeine concentrations. The second curve from the bottom (green) represents the results from human enzyme, and the other three are those from the bacterial sources. In each case the results show the same trend; as the percent caffeine is increased in the enzyme solution, the percent of active enzyme drops. Also, the effect is most pronounced at lower enzyme concentrations than at higher concentrations. The bottom curve (blue) represents results from the weakest enzyme concentration with a sharp drop in the activity value, whereas the upper most curve is due to the most concentrated enzyme solution with much less pronounced effect of caffeine concentration. For the bottom curve, the largest drop in value takes place from $0.0 \%$ to $0.1 \%$ of caffeine, and then, shows almost no change in the value at higher concentrations of caffeine.

Based on the two-step inactivation model (eqns $1 \& 2$ ) we can provide a possible explanation for the inactivation of the enzyme by caffeine. There is a possibility that a caffeine molecule binds with the apo-enzyme $\left(\mathrm{E}^{2-}\right)$, and thus, promotes the metal dissociation from the active enzyme (eqn 1), and hence, causes inactivation. As caffeine concentration is increased, at some point the caffeine molecules saturate the enzyme binding sites, causing maximum inactivation effect, and beyond that point, no significant caffeine effect can be noticed. This is why the bottom curve of Figure 2 representing $0.15 \mathrm{mg} / \mathrm{L}$ of enzyme (bacterial) levels off at around $0.1 \%$ caffeine, whereas the third curve from the bottom representing $0.30 \mathrm{mg} / \mathrm{L}$ of enzyme (bacterial) levels off at around $0.2 \%$ of caffeine. 
Percent Active Enzyme Bacillus $25^{\circ} \mathrm{C}$
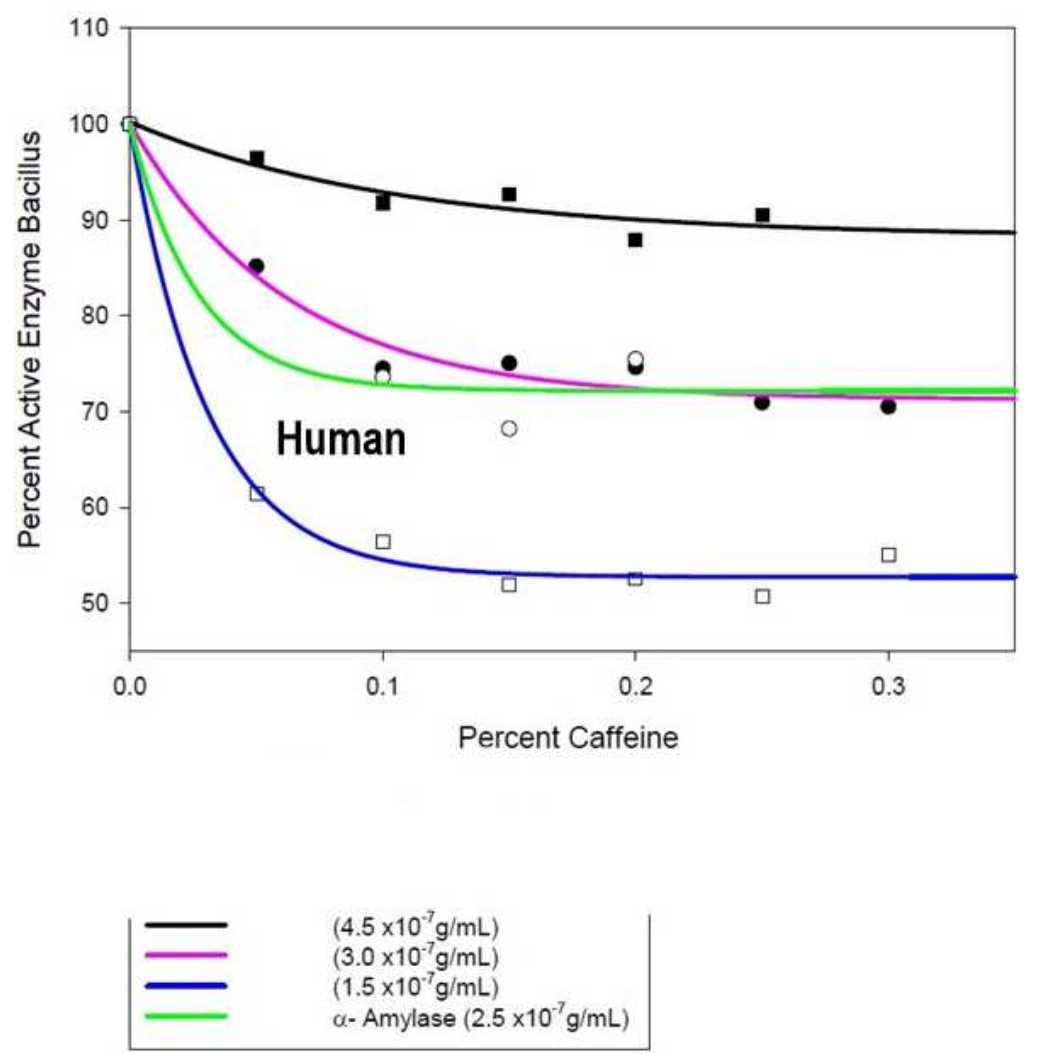

Figure 2. Percent caffeine against Percent active enzyme values are plotted for both human (second green curve from the bottom) as well as bacterial enzyme with protein concentrations ranging from 0.15 to $0.45 \mathrm{mg} / \mathrm{L}$. The caffeine effect is the largest for the most dilute enzyme solution, and the smallest for the most concentrated enzyme solution.

\section{Concluding Comments}

Caffeine inactivates $\alpha$-amylases from various sources. For a particular enzyme concentration, as the caffeine concentration is increased, the amount of inactivation is increased, which finally levels off. As the enzyme is inactivated, the hydrolysis of starch liberates a smaller amount of sugar. This finding may indicate a positive health benefit of caffeine.

\section{References}

[1] D. J. Manners "Enzymic synthesis and degradation of starch and glycogen" Adv. Carbohydr. Chem. Volume 17, pp 371430, 1962 .

[2] K. Kakiuchi, S. Kato, A. Imanishi, and T. Isemura "Association and Dissociation of Bacillus subtilis $\alpha$-Amylase Molecule" J. Biochem, Volume 55, No. 2, pp 102-109, 1964.

[3] J. A. Thoma, J. E. Spradlin, and S. Dygert "6 Plant and Animal Amylases” The Enzymes P. D. Boyer Edition, Volume 5, pp 115-189, 1971.

[4] T. Takagi, H. Toda and T. Isemura "Bacterial and mold amylases" The Enzymes P. D. Boyer Edition, Volume 5, pp 235-271, 1971.
[5] J. R. Whitaker "Principles of Enzymology for the Food Sciences" pp 433-467, 1972.

[6] E. Boel, L. Brady, A. M. Brzozowski, Z. Derewenda, G. G. Dodson, V. J. Jensen, S. B. Petersen, H. Swift, L. Thim, and H. F. Woldike "Calcium binding in alpha-amylases: an x-ray diffraction study at 2.1-. ANG. resolution of two enzymes from Aspergillus" Biochemistry, Volume 29, pp 6244-6249, 1990.

[7] A. K. Chandel, R. Rudravaram, L. V. Rao, R. Pogaku, and M. L. Narasu "Industrial enzymes in bioindustrial sector development: An Indian perspective, J. Comm. Biotechnol. Volume 13, No. 4, pp 283-291, 2007.

[8] D. N. Lecker, and A. Khan "Theoretical and experimental studies of the effects of heat, EDTA, and enzyme concentration on the inactivation rate of $\alpha$-amylase from Bacillus sp.” Biotechnol. Prog. Volume 12, pp 713-717, 1996.

[9] D. N. Lecker and A. Khan, "Model for inactivation of $\alpha$ amylase in the presence of salts: theoretical and experimental studies” Biotechnol. Prog. Volume 14, pp 621-625, 1998.

[10] O. Fagain, "Understanding and increasing protein stability". Biochem Biophys Acta. 1252, pp 1-14, 1995.

[11] V. T. Calabrese, J. W. Minns, and A. Khan, "Suppression of $\alpha$ amylase inactivation in the presence of ethanol: Application of a two-step model", Biotechnol. Prog., 32, pp 1271- 1275 (2016). 